Article

\title{
Decorative Magnolia Plants: A Comparison of the Content of Their Biologically Active Components Showing Antimicrobial Effects
}

\author{
Petra Lovecká ${ }^{1, *}$, Alžběta Svobodová ${ }^{1}$, Anna Macůrková ${ }^{1}$, Blanka Vrchotová ${ }^{1}$, \\ Kateřina Demnerová ${ }^{1}$ and Zdeněk Wimmer ${ }^{2,3}$ \\ 1 Department of Biochemistry and Microbiology, University of Chemistry and Technology in Prague, \\ Technická 3, 16628 Prague 6, Czech Republic; svobodoz@vscht.cz (A.S.); anna.macurkova@vscht.cz (A.M.); \\ blanka.vrchotova@vscht.cz (B.V.); demnerok@vscht.cz (K.D.) \\ 2 Department of Chemistry of Natural Compounds, University of Chemistry and Technology in Prague, \\ Technická 5, 16628 Prague 6, Czech Republic; wimmerz@vscht.cz \\ 3 Isotope Laboratory, Institute of Experimental Botany, Czech Academy of Sciences, Vídeňská 1083, \\ 14220 Prague 4, Czech Republic \\ * Correspondence: loveckap@vscht.cz; Tel.: +420-220-445-139
}

Received: 19 May 2020; Accepted: 9 July 2020; Published: 11 July 2020

\begin{abstract}
Magnolia plants are used both as food supplements and as cosmetic and medicinal products. The objectives of this work consisted of preparing extracts from leaves and flowers of eight Magnolia plants, and of determining concentrations of magnolol (1 to $\left.100 \mathrm{mg} \cdot \mathrm{g}^{-1}\right)$, honokiol $\left(0.11\right.$ to $\left.250 \mathrm{mg} \cdot \mathrm{g}^{-1}\right)$, and obovatol ( 0.09 to $\left.650 \mathrm{mg} \cdot \mathrm{g}^{-1}\right)$, typical neolignans for the genus Magnolia, in extracts made by using a methanol/water (80/20) mixture. The tested Magnolia plants, over sixty years old, were obtained from Průhonický Park (Prague area, Czech Republic): M. tripetala MTR 1531, M. obovata MOB 1511, and six hybrid plants Magnolia $\times$ pruhoniciana, results of a crossbreeding of $M$. tripetala MTR 1531 with M. obovata MOB 1511. The identification of neolignans was performed by HRMS after a reversed-phase high-performance liquid chromatography (RP-HPLC) fractionation of an extract from M. tripetala MTR 1531. The highest concentrations of neolignans were found in the flowers, most often in their reproductive parts, and obovatol was the most abundant in every tested plant. The highest concentrations of neolignans were detected in parent plants, and lower concentrations in hybrid magnolias. Flower extracts from the parent plants M. tripetala MTR 1531 and M. obovata MOB 1511, flower extracts from the hybrid plants Magnolia $\times$ pruhoniciana MPR 0271, MPR 0151, and MPR 1531, and leaf extract from the hybrid plant Magnolia $\times$ pruhoniciana MPR 0271 inhibited growth of Staphylococcus aureus.
\end{abstract}

Keywords: Magnolia genus; Staphylococcus aureus; medium-polar extract; neolignan; magnolol; obovatol; honokiol; antimicrobial activity

\section{Introduction}

Magnolia plants have been grown for decorative purposes in Europe and America, while in Asia these plants (especially M. officinalis and M. obovata) have been used in traditional medicine for centuries in order to treat gastrointestinal disorders, anxiety, cough, allergies, or asthma [1].

The biological and healing effects of plants appear due to their secondary metabolites, which protect plants from the effects of the external environment. Knowledge about the medicinal effects from traditional medicine has resulted in a great interest in determining the plant metabolites that display biological effects for their expected applications-not only for the preparation of medicinal products, but also for their use as food supplements or biopesticides [2-5]. 
Antimicrobial, antioxidant, antitumor, and neuroprotective effects or cardiovascular protective effects have been demonstrated with many secondary metabolites of the genus Magnolia [5-7]. Those authors summarized the results of 58 selected studies on the biological activity of Magnolia plants. The effects of the substances were the most evident in the area of metabolism (37.5\%), in the central nervous system $(25 \%)$, and in cardiovascular treatment $(20.8 \%)$.

At least 225 biologically active substances, among which are lignans, neolignans, terpenoids, and alkaloids, have been described in the Magnolia genus [2,6,7]. The most commonly studied secondary metabolites of this genus include neolignans, namely magnolol, honokiol, and obovatol. Ninety percent of the biological effects of Magnolia plants are mediated by the most frequent plant secondary metabolites, i.e., magnolol and honokiol [1,8].

The increase in the concentration of secondary metabolites with the growing age of the plant occurs mainly in its bark, which plays a significant role in the production of medicinal products from Magnolia. To prepare such products from the bark of M. officinalis, the plant must be older than 15 years. However, subsequent peeling of the bark, which can also be obtained from the root of the plant, may result in a threat or even in an extermination of the plant source.

In recent years, and not only for the above-mentioned reason, investigation has been focused on analyzing quantities of secondary metabolites in parts of Magnolia plants other than its bark [6,7]. Leaves should be available sources of useful substances in these plants, which could be subject to danger if they are torn apart, in order to protect them from damage that could occur during the harvesting of their bark. However, magnolol and honokiol were found in only one-fifth quantities in comparison to their concentration in the bark [7,9-11].

The objectives of this work consisted of (a) preparing extracts from leaves and flowers of eight Magnolia plants, (b) analyzing the concentration of magnolol, honokiol, and obovatol, neolignans typical for the genus Magnolia, obtained by extraction using a methanol/water (80/20, v/v) mixture and subsequent extraction of the organic layer by chloroform, and (c) determining the antimicrobial effects of the extracts. The studied plant material consisted of Magnolia plants that were over sixty years old from Průhonice Park: the parent plants M. tripetala MTR 1531 and M. obovata MOB 1511 and six hybrids resulting from their crossbreeding, Magnolia $\times$ pruhoniciana.

\section{Results}

The extract from M. tripetala MTR 1531 flowers, made by using a methanol/water (80/20, $v / v)$ mixture and subsequent extraction of the organic layer by chloroform, was fractionated by reversed-phase high-performance liquid chromatography (RP-HPLC). Six elution zones were detected in the chromatograms, showing their retention times at $6.3 \mathrm{~min}, 44.1 \mathrm{~min}, 45.5 \mathrm{~min}, 46.0 \mathrm{~min}, 47.5 \mathrm{~min}$, and $48.0 \mathrm{~min}$. These fractions were subjected to a high-resolution mass spectrometry analysis (UPLC-QTOF HRMS/MS analysis). The investigated neolignans were identified in the only three fractions (fraction 2 (honokiol), fraction 3 (obovatol), and fraction 4 (magnolol); Figure 1). The remaining three fractions were not identified (Table 1).

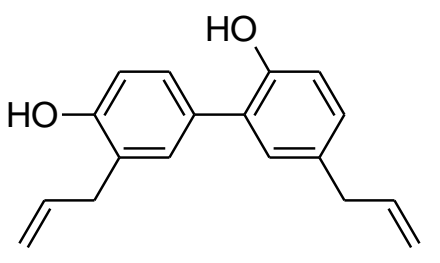

honokiol
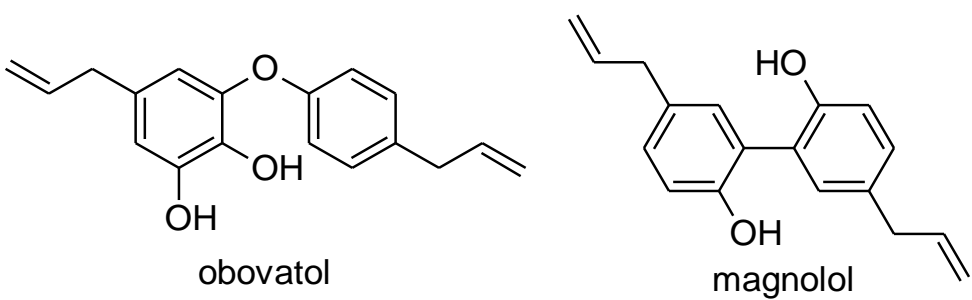

Figure 1. The structures of honokiol, obovatol, and magnolol. 
Table 1. Identification and retention times of compounds in the fractions 1-6.

\begin{tabular}{cccc}
\hline Fraction & RT $^{\text {a }}$ & Identified Substance & Main Mass Fragments $(\mathrm{m} / \mathbf{z})$ \\
\hline 1 & $6.3 \mathrm{~min}$ & unidentified & - \\
2 & $44.1 \mathrm{~min}$ & honokiol & $209.0597 ; 224.0844 ; 250.0999$ \\
3 & $45.5 \mathrm{~min}$ & obovatol & $133.0657,164.0478 .240 .0775$ \\
4 & $46.0 \mathrm{~min}$ & magnolol & $223.0785 ; 245.0968,247.1124$ \\
5 & $47.5 \mathrm{~min}$ & unidentified & - \\
6 & $48.0 \mathrm{~min}$ & unidentified & - \\
\hline
\end{tabular}

${ }^{\text {a }}$ RT = approximate retention time of collecting the fractions by RP-HPLC.

The identification of magnolol and honokiol was performed by comparing the fragmentation of their mass spectra with the records in the METLIN online database. The mass spectrum of obovatol was not available from the METLIN database; however, this neolignan was identified based on data published in a paper [12], in which the fragmentation spectrum of obovatol was published.

On the basis of the calibration curve for the identified substances, the concentrations of the monitored neolignans in individual extracts were measured using an RP-HPLC method. A summarizing evaluation of the concentrations of honokiol, obovatol, and magnolol in individual parts of plants is given in Table 2.

Table 2. Concentrations of honokiol, obovatol, and magnolol in the given parts of the individual plants ${ }^{\text {a }}$.

\begin{tabular}{|c|c|c|c|c|c|}
\hline & Plant & Part of Plant & $\begin{array}{c}\text { Honokiol } \\
\text { (mg.g }{ }^{-1} \text { Dry Mass) }\end{array}$ & $\begin{array}{c}\text { Obovatol } \\
\text { (mg.g }{ }^{-1} \text { Dry Mass) }\end{array}$ & $\begin{array}{c}\text { Magnolol } \\
\text { (mg.g }{ }^{-1} \text { Dry Mass) }\end{array}$ \\
\hline \multirow{18}{*}{$\begin{array}{c}\text { Magnolia hybrid } \\
\text { plants }\end{array}$} & \multirow[t]{3}{*}{ MPR 0131} & $\mathrm{~L}$ & $3.64 \pm 0.04$ & $0.68 \pm 0.05$ & $1.01 \pm 0.08$ \\
\hline & & FP & $7.25 \pm 0.01$ & $8.98 \pm 0.2$ & $2.95 \pm 0.00$ \\
\hline & & SP & $47.43 \pm 7.11$ & $92.13 \pm 13.82$ & $25.81 \pm 3.87$ \\
\hline & \multirow[t]{3}{*}{ MPR 0151} & $\mathrm{~L}$ & $2.01 \pm 0.02$ & $0.90 \pm 0.01$ & $0.76 \pm 0.01$ \\
\hline & & FP & $13.01 \pm 1.95$ & $24.59 \pm 3.69$ & $6.00 \pm 0.90$ \\
\hline & & SP & $35.95 \pm 5.39$ & $80.67 \pm 12.10$ & $18.79 \pm 2.82$ \\
\hline & \multirow[t]{3}{*}{ MPR 0271} & $\mathrm{~L}$ & $0.39 \pm 0.06$ & $0.09 \pm 0.01$ & $0.21 \pm 0.03$ \\
\hline & & FP & $13.04 \pm 1.96$ & $26.28 \pm 3.94$ & $5.91 \pm 0.89$ \\
\hline & & SP & $47.25 \pm 7.09$ & $115.57 \pm 17.34$ & $22.51 \pm 3.38$ \\
\hline & \multirow[t]{3}{*}{ MPR 1501} & $\mathrm{~L}$ & $3.03 \pm 0.01$ & $1.85 \pm 0.03$ & $1.26 \pm 0.01$ \\
\hline & & FP & $25.23 \pm 3.78$ & $37.38 \pm 5.61$ & $10.41 \pm 1.56$ \\
\hline & & SP & $55.34 \pm 8.30$ & $117.49 \pm 17.62$ & $28.24 \pm 4.24$ \\
\hline & \multirow[t]{3}{*}{ MPR 1511} & $\mathrm{~L}$ & $8.26 \pm 1.24$ & $2.21 \pm 0.33$ & $2.07 \pm 0.31$ \\
\hline & & $\mathrm{FP}$ & $13.09 \pm 1.96$ & $19.84 \pm 2.98$ & $6.49 \pm 0.97$ \\
\hline & & SP & $26.10 \pm 3.91$ & $60.43 \pm 9.06$ & $13.15 \pm 1.97$ \\
\hline & \multirow[t]{3}{*}{ MPR 1531} & $\mathrm{~L}$ & $0.11 \pm 0.02$ & $0.06 \pm 0.01$ & $0.06 \pm 0.01$ \\
\hline & & FP & $18.90 \pm 2.84$ & $22.86 \pm 3.43$ & $8.30 \pm 1.24$ \\
\hline & & SP & $17.13 \pm 2.57$ & $39.95 \pm 5.99$ & $10.54 \pm 1.58$ \\
\hline \multirow{6}{*}{$\begin{array}{l}\text { Magnolia parent } \\
\text { plants }\end{array}$} & \multirow[t]{2}{*}{ MOB 1511} & $\mathrm{~L}$ & $0.70 \pm 0.01$ & $54.18 \pm 2.76$ & $5.55 \pm 0.25$ \\
\hline & & FP & $1.74 \pm 0.26$ & $271.63 \pm 40.74$ & $13.04 \pm 1.96$ \\
\hline & \multirow{4}{*}{ MTR 1531} & SP & $4.70 \pm 0.70$ & $649.38 \pm 97.41$ & $30.99 \pm 4.65$ \\
\hline & & $\mathrm{L}$ & $191.62 \pm 28.74$ & $4.03 \pm 0.60$ & $53.61 \pm 8.04$ \\
\hline & & FP & $252.26 \pm 37.84$ & $71.85 \pm 10.78$ & $83.16 \pm 12.47$ \\
\hline & & SP & $230.82 \pm 34.62$ & $269.31 \pm 40.40$ & $99.91 \pm 14.99$ \\
\hline
\end{tabular}

${ }^{\mathrm{a}} \mathrm{MPR}=$ Magnolia $\times$ pruhoniciana, $\mathrm{MOB}=$ M. obovata, $\mathrm{MTR}=$ M. tripetala, $\mathrm{L}=$ leaves, $\mathrm{FP}=$ flower petals, $\mathrm{SP}=$ sexual parts of plants, $\pm \mathrm{SD}$ (standard deviation).

In our investigation, we studied the content of neolignans in leaves and flowers of Magnolia plants, and we found that the flowers of the tested Magnolia plants were richer in neolignans than the leaves. The reason for the higher concentration of neolignans in Magnolia plant flowers may be based on their aromatic properties attracting pollinators. The aromatic and spicy aroma of Magnolia plant flowers is attributed to magnolol and honokiol [13].

A common feature of hybrid Magnolia plants and one of the parent plants, M. obovata MOB 1511, was the presence of obovatol, which was a major component in the flowers. Obovatol was identified 
as the main component of M. obovata leaves [14], and it was also confirmed by our measurements, resulting in a finding that $M$. obovata MOB 1511 leaves contained the largest amount of obovatol of the three neolignans studied.

The flowers of some Magnolia plants contained significantly higher quantities of neolignans compared to the reported concentrations of these substances in the bark of Magnolia plants. Scientific literature has reported that the M. officinalis bark extracted with ethanol $(99.5 \%)$ contained $75.2 \mathrm{mg} \cdot \mathrm{g}^{-1}$ of magnolol and $19.1 \mathrm{mg} \cdot \mathrm{g}^{-1}$ of honokiol after HPLC analysis [5]. The M. obovata bark extracted with methanol contained $3.3 \mathrm{mg} \cdot \mathrm{g}^{-1}$ of obovatol $[1,15]$. In our measurements, the flower (flower petals and sexual parts of the plants together) of $M$. tripetala MTR 1531 contained $183.07 \mathrm{mg} \cdot \mathrm{g}^{-1}$ of magnolol and $483.08 \mathrm{mg} \cdot \mathrm{g}^{-1}$ of honokiol, whereas the $M$. obovata MOB 1511 flower contained $921 \pm 138.15 \mathrm{mg} \cdot \mathrm{g}^{-1}$ obovatol. In another study on the content of secondary metabolites in Magnolia plants, the concentration of magnolol and honokiol in the leaves taken from seventeen plants of $M$. officinalis var. biloba grown in different regions of China was investigated. This plant is one of the subspecies, known to M. officinalis, and it is also used in traditional medicine. The mean content of the substances in the leaf samples was determined by HPLC analysis of methanol extracts as $0.23 \mathrm{mg} \mathrm{g}^{-1}$ of magnolol and $1.14 \mathrm{mg} \mathrm{g}^{-1}$ of honokiol [16].

The Magnolia leaves analyzed in our work showed higher concentrations of the studied compounds than it was found by other authors in the Magnolia leaves [16]. The highest concentration of the studied compounds measured in $M$. tripetala leaves was found as $53.61 \mathrm{mg} \cdot \mathrm{g}^{-1}$ of magnolol and $191.62 \mathrm{mg} \cdot \mathrm{g}^{-1}$ of honokiol.

The concentration of neolignans in hybrid plants of Magnolia $\times$ pruhoniciana has not yet been documented, and our work resulted in a new finding that parent plants contain considerably larger amounts of observed neolignans than hybrid plants. For example, the flowers of $M$. tripetala contained more than ten times the amount of honokiol compared to hybrid Magnolia flowers. Yet, when compared to the content of neolignans in M. officinalis bark [5], the Magnolia $\times$ pruhoniciana hybrids appear to be a rich source of honokiol and obovatol, and therefore a more detailed analysis of these plant parts is appropriate due to the possible content of other useful metabolites, not yet known or studied [17-19].

One of the properties of Magnolia plants is their antimicrobial effect, which was also one of the objectives studied in our work. The tested bacterium Staphylococcus aureus is one of the human pathogens causing life-threatening infectious diseases, such as pneumonia, or serious skin diseases with subsequent toxic shock syndrome. With the increasing resistance of bacteria (including S. aureus) to antibiotics, other possible ways of treatment have been intensively sought $[9,20]$.

Antimicrobial activity values were measured for individual extracts, i.e., mixtures of the compounds contained therein. Substances in extracts can interact with each other, often acting in a synergy. The synergic effect of magnolol and honokiol has already been reported in the literature [1].

In most of the extracts tested, the concentration of $125 \mu \mathrm{g} \cdot \mathrm{mL}^{-1}$, in some cases a concentration of $62.5 \mu \mathrm{g} \cdot \mathrm{mL}^{-1}$, showed the highest inhibitory activity. The inhibition coefficients of these concentrations of individual extracts are given in Table 3. Leaves of some plants (e.g., leaves of Magnolia $\times$ pruhoniciana MPR 0271) also achieved high growth inhibition of the tested bacteria at a concentration of $125 \mu \mathrm{g} \cdot \mathrm{mL}^{-1}$.

As shown in Table 3, only extracts from flowers and, in one case, from leaves inhibited the growth of S. aureus by $100 \%$, and it was possible to determine minimum inhibitory concentration (MIC) and to calculate $\mathrm{IC}_{50}$ values. Among the hybrid Magnolia plants, $100 \%$ inhibition of bacterial growth was caused by extracts from the flowers of Magnolia $\times$ pruhoniciana MPR 0131, 0151, and 1531 plants and Magnolia $\times$ pruhoniciana MPR 0271 leaves, and, specifically, the extracts from the sexual parts of the flowers of M. obovata MOB 1511, and the two tested parts of the flowers of M. tripetala MTR 1531. MIC and $\mathrm{IC}_{50}$ values were further determined for the tested extracts. The results are summarized in Table 4. 
Table 3. Percentages of growth inhibition I (\%) of Staphylococcus aureus by extracts from different parts of Magnolia plants in different concentrations ${ }^{\mathrm{a}}$.

\begin{tabular}{|c|c|c|c|c|}
\hline & \multirow{2}{*}{ Plant } & \multirow{2}{*}{ Part of Plant } & \multicolumn{2}{|c|}{ I (\%) for Concentration of Extract } \\
\hline & & & $125 \mu \mathrm{g} \cdot \mathrm{mL}^{-1}$ & $62.5 \mu \mathrm{g} \cdot \mathrm{mL}^{-1}$ \\
\hline \multirow{18}{*}{$\begin{array}{l}\text { Magnolia hybrid } \\
\text { plants }\end{array}$} & \multirow[t]{3}{*}{ MPR 0131} & $\mathrm{~L}$ & $63.3 \pm 3.7$ & $54.3 \pm 1.4$ \\
\hline & & FP & $98.3 \pm 3.2$ & $84.9 \pm 1.8$ \\
\hline & & $\mathrm{SP}$ & $100.0 \pm 7.2$ & $81.7 \pm 2.1$ \\
\hline & \multirow[t]{3}{*}{ MPR 0151} & $\mathrm{~L}$ & $88.4 \pm 2.2$ & $81.4 \pm 4.0$ \\
\hline & & FP & $96.1 \pm 1.8$ & $13.9 \pm 5.0$ \\
\hline & & $\mathrm{SP}$ & $97.2 \pm 3.3$ & $77.1 \pm 2.5$ \\
\hline & \multirow[t]{3}{*}{ MPR 0271} & $\mathrm{~L}$ & $98.4 \pm 1.8$ & $62.5 \pm 2.1$ \\
\hline & & FP & $97.0 \pm 0.8$ & $15.0 \pm 4.7$ \\
\hline & & SP & $95.9 \pm 0.5$ & $62.5 \pm 4.0$ \\
\hline & \multirow[t]{3}{*}{ MPR 1501} & $\mathrm{~L}$ & $56.2 \pm 1.2$ & $57.1 \pm 5.8$ \\
\hline & & FP & $84.5 \pm 2.1$ & $83.9 \pm 2.4$ \\
\hline & & $\mathrm{SP}$ & $93.6 \pm 4.6$ & $87.9 \pm 7.9$ \\
\hline & \multirow[t]{3}{*}{ MPR 1511} & $\mathrm{~L}$ & $51.4 \pm 3.0$ & $53.5 \pm 6.4$ \\
\hline & & FP & $42.9 \pm 4.4$ & $0.0 \pm 0.0$ \\
\hline & & $\mathrm{SP}$ & $96.6 \pm 1.4$ & $82.7 \pm 4.0$ \\
\hline & \multirow[t]{3}{*}{ MPR 1531} & $\mathrm{~L}$ & $64.3 \pm 3.6$ & $34.5 \pm 4.0$ \\
\hline & & FP & $100.0 \pm 2.0$ & $37.2 \pm 9.6$ \\
\hline & & $\mathrm{SP}$ & $94.1 \pm 0.3$ & $48.8 \pm 4.1$ \\
\hline \multirow{6}{*}{$\begin{array}{l}\text { Magnolia parent } \\
\text { plants }\end{array}$} & \multirow[t]{2}{*}{ MOB 1511} & $\mathrm{~L}$ & $80.4 \pm 17.7$ & $58.4 \pm 11.3$ \\
\hline & & FP & $65.1 \pm 3.5$ & $41.8 \pm 6.7$ \\
\hline & \multirow{4}{*}{ MTR 1531} & SP & $98.4 \pm 2.9$ & $100.0 \pm 4.0$ \\
\hline & & $\mathrm{L}$ & $66.6 \pm 18.8$ & $68.7 \pm 3.8$ \\
\hline & & FP & $65.4 \pm 3.9$ & $100.0 \pm 4.6$ \\
\hline & & SP & $92.0 \pm 6.7$ & $68.6 \pm 35.6$ \\
\hline
\end{tabular}

${ }^{a} \mathrm{MPR}=$ Magnolia $\times$ pruhoniciana, $\mathrm{MOB}=M$. obovata, $\mathrm{MTR}=M$. tripetala, $\mathrm{L}=$ leaves, $\mathrm{FP}=$ flower petals, $\mathrm{SP}=$ sexual parts of plants, $\pm \mathrm{SD}$ (standard deviation).

Table 4. MIC $\left(\mu \mathrm{g} \cdot \mathrm{mL}^{-1}\right)$ and $\mathrm{IC}_{50}\left(\mu \mathrm{g} \cdot \mathrm{mL}^{-1}\right)$ of tested extracts for the bacterium S. aureus ${ }^{\mathrm{a}}$.

\begin{tabular}{|c|c|c|c|c|}
\hline & Plant & Part of Plant & $\mathrm{IC}_{50}\left(\mu \mathrm{g} \cdot \mathrm{mL}^{-1}\right)$ & $\operatorname{MIC}^{b}\left(\mu \mathrm{g} \cdot \mathrm{mL}^{-1}\right)$ \\
\hline \multirow{18}{*}{$\begin{array}{l}\text { Magnolia hybrid } \\
\text { plants }\end{array}$} & \multirow[t]{3}{*}{ MPR 0131} & $\mathrm{~L}$ & - & $>125$ \\
\hline & & FP & $56.6 \pm 0.8^{c}$ & $125 \pm 6.3$ \\
\hline & & SP & $46.9 \pm 2.0^{c}$ & $125 \pm 6.3$ \\
\hline & \multirow[t]{3}{*}{ MPR 0151} & $\mathrm{~L}$ & 002D & 125 \\
\hline & & FP & - & $>125$ \\
\hline & & SP & $57.6 \pm 0.1^{c}$ & $125 \pm 6.3$ \\
\hline & \multirow[t]{3}{*}{ MPR 0271} & $\mathrm{~L}$ & $62.9 \pm 10.9^{c}$ & $125 \pm 6.3$ \\
\hline & & $\mathrm{FP}$ & - & $>125$ \\
\hline & & SP & - & $>125$ \\
\hline & \multirow[t]{3}{*}{ MPR 1501} & $\mathrm{~L}$ & - & $>125$ \\
\hline & & FP & - & $>125$ \\
\hline & & SP & - & $>25$ \\
\hline & \multirow[t]{3}{*}{ MPR 1511} & $\mathrm{~L}$ & - & $>125$ \\
\hline & & FP & - & $>125$ \\
\hline & & SP & - & $>125$ \\
\hline & \multirow[t]{3}{*}{ MPR 1531} & $\mathrm{~L}$ & - & $>125$ \\
\hline & & $\mathrm{FP}$ & $71.0 \pm 5.4^{\mathrm{c}}$ & $125 \pm 6.3$ \\
\hline & & SP & - & $>125$ \\
\hline \multirow{6}{*}{$\begin{array}{l}\text { Mgnolia parent } \\
\text { plants }\end{array}$} & \multirow[t]{2}{*}{ MOB 1511} & $\mathrm{~L}$ & - & $>125$ \\
\hline & & FP & - & $>125$ \\
\hline & \multirow{4}{*}{ MTR 1531} & SP & $40.1 \pm 7.4^{c}$ & $62.5 \pm 3.1$ \\
\hline & & $\mathrm{L}$ & - & $>125$ \\
\hline & & FP & $31.6 \pm 0.2^{c}$ & $62.5 \pm 3.1$ \\
\hline & & SP & $60.2 \pm 26.4^{c}$ & $62.5 \pm 3.1$ \\
\hline
\end{tabular}

${ }^{a} \mathrm{MPR}=$ Magnolia $\times$ pruhoniciana, $\mathrm{MOB}=M$. obovata, $\mathrm{MTR}=M$. tripetala, $\mathrm{L}=$ leaves, $\mathrm{FP}=$ flower petals, $\mathrm{SP}=$ sexual parts of plants, $\pm \mathrm{SD}$ (standard deviation), ${ }^{\mathrm{b}} \mathrm{MIC}$ (vancomycin) $=1 \mu \mathrm{g} \cdot \mathrm{ml}^{-1}$, ${ }^{\mathrm{c}}$ Significantly $(p<0.05)$ different from the control. 
A study by Kim [20] investigated the antibacterial effect of magnolol from M. officinalis bark extract against methicillin-resistant S. aureus (MRSA). Magnolol was obtained by an HPLC separation of the extract. The study described its promising effects and concluded with the potential use of magnolol in conjunction with antibiotics, which could lead to a development of new drugs against MRSA infection [20].

In our work, the antibacterial activity of extracts from individual plant parts of Magnolia was studied, but not that of individual neolignans. Thus, the effects observed cannot be attributed to a particular compound. Extracts from the sexual parts of parent plants MOB 1511 showed MIC values with respect to $S$. aureus of up to $40.1 \mu \mathrm{g} \cdot \mathrm{mL}^{-1}$. The MIC values with respect to this bacterium, taken from the literature and in which the $M$. officinalis bark extract was tested, were reported to be about $20 \mu \mathrm{g} \cdot \mathrm{mL}^{-1}[21]$.

\section{Conclusions}

Our study showed that the tested Magnolia blossom extracts contained higher concentrations of honokiol and obovatol than those reported in M. officinalis and M. obovata bark samples commonly used, from which a number of products are currently being prepared. These extracts very effectively inhibited the growth of S. aureus. A synergic effect of the studied plant products in the inhibition of growth of S. aureus was also observed. The beautiful flowers of decorative Magnolia plants containing suitable biologically active substances have proven their potential for practical pharmacological application and, therefore, the very useful reason to plant these flowers, in addition to their role of providing pleasure and a garden decoration in European areas.

\section{Experimental Section}

\subsection{Plant Material}

The plant material described above and used included parent plants (designated MTR 1531 and MOB 1511) and six hybrid Magnolia plants (designated MPR). The plants came from the Prühonice Park (49 $59^{\prime} 25.81^{\prime \prime} \mathrm{N}, 14^{\circ} 32^{\prime} 41.23^{\prime \prime}$ E) in the Czech Republic.

Hybrids were created by the common crossbreeding of $M$. tripetala and M. obovata, i.e., pollination of the flowers of one species with the pollen of another. Crossbreeding was done in the Prühonice Park by Viktor Keskevič before 1952.

\subsection{Preparation of Extracts}

Leaves, petals, and sexual parts of the flowers were taken from each Magnolia plant separately (10 flower pieces and the leaves of 3 trees). These plant parts were treated by freeze-drying (8.4 Pa, $-54{ }^{\circ} \mathrm{C}$ ) and then ground. A smaller amount was weighed out from each of the Magnolia portions treated (1.5 g for most plants) and diluted with $80 \%$ methanol. The homogenization of the material for subsequent extraction was performed by disintegration $(130 \mathrm{MPa})$ of these suspensions using the ONE SHOT MODEL homogenizer (Constant Systems Ltd., Daventry, UK).

After disintegration, the suspensions from leaves, petals, and sexual parts of the flowers of each plant were washed with water six times in succession and the pellets obtained were resuspended in $80 \%$ methanol. The pellets and solutions were further processed according to a standardized procedure for extracting secondary metabolites with different organic solvents, $\mathrm{pH}$, and polarity [22]. The extracts obtained were evaporated using a CentriVap refrigerated rotary concentrator (LABCONCO, Kansas City, MO, USA) $\left(35^{\circ} \mathrm{C}\right)$, dried, weighed, and diluted with $100 \%$ methanol to stock solutions for subsequent measurements. 


\subsection{RP-HPLC Analysis}

Magnolol, honokiol, and obovatol (Figure 1) were identified, and quantified in the extracts made using a methanol/water $(80 / 20, v / v)$ mixture, obtained after acidification (to $\mathrm{pH}=2$ ), and subsequent extraction of the organic layer by chloroform.

Identification of these three compounds was performed by high-resolution mass spectrometry. Identification of substances was performed on a 6560 Ion Mobility Q-TOF system (Agilent Technologies, Santa Clara, CA, USA). Aliquots $(2 \mu \mathrm{L})$ of extracts were sprayed into an Agilent Infinity 1290 liquid chromatograph (Agilent Technologies, Santa Clara, CA, USA) with an Acquity UPLC BEH C18 $(100 \times 2.1$ (i.d.) $\mathrm{mm}$, particle size $1.7 \mu \mathrm{m}$ ) analytical column (Waters Corporation, Milford, MA, USA). The column temperature was $60^{\circ} \mathrm{C}$, and the flow rate was set up to $0.35 \mathrm{ml} \cdot \mathrm{min}^{-1}$.

The mobile phase A consisted of $5 \mathrm{mM}$ ammonium formate in a mixture of methanol/water (95/5, $v / v)$ containing $0.1 \%$ of formic acid. The mobile phase B consisted of $5 \mathrm{mM}$ ammonium formate in an isopropyl alcohol $/ \mathrm{methanol} /$ water $(65 / 30 / 5, v / v)$ mixture, containing $0.1 \%$ of formic acid.

The substances were detected based on the exact mass $(\mathrm{m} / \mathrm{z})$ of their $[\mathrm{M}-\mathrm{H}]^{-}$ion, the isotopic profile in the MS1 mass spectrum, and the specific fragmentation spectrum (the presence of specific fragments and their representation in the spectrum). A quadrupole/fly-through analyzer (Agilent Technologies, Santa Clara, CA, USA) was used for detection. Measured fragmentation spectra of substances, at collision energy (AutoMS/MS; $20 \mathrm{eV}$ ), were compared with the records in the METLIN online database and in the literature. Isolated pure magnolol, honokiol, and obovatol were used for calibration purposes.

Their concentration in individual extracts was analyzed by reversed-phase high-performance liquid chromatography (RP-HPLC). Samples $\left(0.5 \mathrm{mg} \cdot \mathrm{mL}^{-1} ; 10 \mu \mathrm{L}\right)$ were injected into an Agilent 1100 liquid chromatograph with a Discovery ${ }^{\circledR} \mathrm{C}-18(250 \times 4.6$ (i.d.) $\mathrm{mm}$; particle size $5 \mu \mathrm{m})$ chromatographic separatory column (Aldrich, St. Louis, MO, USA). Methanol and a solution of $10 \mathrm{mM}$ formic acid in water were used as mobile phase (Table 5).

Table 5. Elution gradient.

\begin{tabular}{ccc}
\hline Time (min) & Methanol & 10 $\mathbf{~ m M ~ F o r m i c ~ A c i d ~}$ \\
\hline 2 & $5 \%$ & $95 \%$ \\
45 & $90 \%$ & $10 \%$ \\
50 & $100 \%$ & $0 \%$ \\
60 & $100 \%$ & $0 \%$ \\
65 & $5 \%$ & $95 \%$ \\
\hline
\end{tabular}

Each individual measurement took $80 \mathrm{~min}$ with the mobile phase flow rate of $1 \mathrm{~mL} \cdot \mathrm{min}^{-1}$. The UV spectra were taken on a diode array detector (DAD) (Life Science UV/VIS Spectrophotometer DU 730, Beckman Coulter, Carlsbad, CA, USA) at 220 and $280 \mathrm{~nm}$.

Fractions were prepared for identification of magnolol, honokiol, and obovatol by high-resolution mass spectrometry, and then the concentration of neolignans in the extracts from plant parts of the tested Magnolia plants was determined. For calibration purposes, isolated pure magnolol, honokiol, obovatol were used as reference compounds.

\subsection{Antimicrobial Activity of Extracts}

The spectrophotometric method was used for the determination of antimicrobial activity. The optical density (OD) of individual suspensions containing the tested extracts and the bacterium Staphylococcus aureus was measured at $625 \mathrm{~nm}$.

The result of the method was the dependence of OD on the time-growth curve of the microorganism, which was influenced to some extent by added test extracts.

S. aureus was cultured on TSA $\left(37^{\circ} \mathrm{C}\right)$ overnight. Then, one colony was picked up and diluted with Ringer's solution to $\mathrm{OD}_{625}=0.1$. The prepared suspension, containing approximately 
$2 \times 10^{9} \mathrm{CFU} \cdot \mathrm{mL}^{-1}$, was further diluted several times. Each well of the microtiter plate then contained $5 \times 10^{4} \mathrm{CFU}$.

From the stock solutions of medium-polar extracts at a concentration of $10 \mathrm{mg} \cdot \mathrm{mL}^{-1}$, aliquot parts of $250 \mu \mathrm{g} \cdot \mathrm{mL}^{-1}$ solutions were prepared by dilution with Mueller-Hinton broth 2 medium, which was prepared with a concentration of $500 \mu \mathrm{g} \cdot \mathrm{mL}^{-1}$. Solutions of medium-polar extracts from leaves, petals, and sexual parts of flowers were pipetted to the microtiter plate, at concentrations of 0 to $125 \mu \mathrm{g} \cdot \mathrm{mL}^{-1}$. The prepared suspension of $S$. aureus $(50 \mu \mathrm{L})$ was pipetted into each well.

The OD was measured every hour in the period of $24 \mathrm{~h}$ at a growth temperature of $35^{\circ} \mathrm{C}$, i.e., at the temperature recommended by the CLSI for determining the antimicrobial activity of the substances. Growth inhibition of microorganisms was evaluated using Equation (1):

$$
\text { Inhibition }=\left(1-\left(\Delta A_{\text {fraction }} / \Delta A_{\text {control }}\right)\right)^{*} 100
$$

$\Delta A_{\text {fraction }}$-the OD difference at the beginning and at the 18th hour of the measurement of the antimicrobial samples,

$\Delta A_{\text {control }}$ - the OD difference at the beginning and at the 18th hour of the measurement for the unaffected microorganism.

A solution of the antibiotic vancomycin at a concentration of $0.1 \mathrm{mg} \cdot \mathrm{mL}^{-1}$ was used as a positive control.

The measurement was performed in four parallels, and the standard deviation was calculated. Data were analyzed using the statistical functions of SigmaStat 3.0 (SPSS Inc., Chicago, IL, USA). If in a one-way analysis of variance test a significant F-value of $p<0.05$ was obtained, a Dunnett's multiple comparison test between the treated and control groups was conducted. The significance level was established at $p<0.05$ for all statistical tests. An $\mathrm{IC}_{50}$ calculator from AAT Bioquest ${ }^{\circledR}$ was used to calculate the $\mathrm{IC}_{50}$ values (https://www.aatbio.com/tools/ic50-calculator/).

Author Contributions: P.L. designed and supervised the experiments; A.S., A.M., and B.V. made the extractions, performed the analysis, and carried out antimicrobial screening tests; P.L., K.D., and Z.W. prepared and checked the manuscript. All authors have read and agreed to the published version of the manuscript.

Funding: A financial support by the Ministry of Industry and Trade of the Czech Republic, project no. FV30300, is gratefully appreciated.

Conflicts of Interest: The authors declare no conflict of interest.

\section{References}

1. Lee, Y.J.; Lee, Y.M.; Lee, C.-K.; Jung, J.K.; Han, S.B.; Hong, J.T. Therapeutic applications of compounds in the Magnolia family. Pharmacol. Ther. 2011, 130, 157. [CrossRef] [PubMed]

2. Song, Q. A Phytochemical Study of Members of the Genus Magnolia (Magnoliaceae) and Biosynthetic Studies of Secondary Metabolites in Asteraceae Hairy Root Cultures. Ph.D. Thesis, Louisiana State University and Agricultural \& Mechanical College, Baton Rouge, LA, USA, 1995.

3. Cheynier, V.; Comte, G.; Davies, K.M.; Lattanzio, V.; Martens, S. Plant phenolics: Recent advances on their biosynthesis, genetics, and ecophysiology. Plant Physiol. Biochem. 2013, 72, 1. [CrossRef] [PubMed]

4. Özdemir, Z.; Bildziukevich, U.; Wimmerová, M.; Macůrková, A.; Lovecká, P.; Wimmer, Z. Plant adaptogens: Natural medicaments for 21st century? ChemistrySelect 2018, 3, 2196. [CrossRef]

5. Banik, K.; Ranaware, A.M.; Deshpande, V.; Nalawade, S.V.; Padmavathi, G.; Bordoloi, D.; Sailo, B.L.; Shanmugam, M.K.; Fan, L.; Arfuso, F.; et al. Honokiol for cancer therapeutics: A traditional medicine that can modulate multiple oncogenic targets. Pharmacol. Res. 2019, 144, 192. [CrossRef] [PubMed]

6. Sarker, S.D.; Maruyama, Y. Magnolia: The Genus Magnolia; Taylor \& Francis: London, UK, 2002.

7. Vu, V.; Liu, X.; Nguyen, M.; Lin, Y.; Kong, L.; Luo, J. New obovatol trimeric neolignans with NO inhibitory activity from the leaves of Magnolia officinalis var. biloba. Bioorg. Chem. 2020, 96, 103586. [CrossRef] [PubMed] 
8. Cunfang, L.I.U. Determination content of the magnolol from Magnolia officinalia leaves by HPLC. Agric. Bas. Sci. Technol. 2016, 17, 251.

9. Zálešák, F.; Bon, D.J.Y.D.; Pospíšil, J. Lignans and Neolignans: Plant secondary metabolites as a reservoir of biologically active substances. Pharmacol. Res. 2019, 146, 104284. [CrossRef] [PubMed]

10. Luo, H.; Wu, H.; Yu, X.; Zhang, X.; Lu, Y.; Fan, J.; Tang, J.; Wang, Z. A review of the phytochemistry and pharmacological activities of Magnoliae officinalis cortex. J. Ethnopharmacol. 2019, 236, 412. [CrossRef] [PubMed]

11. Zheng, H.Z.; Dong, C.H.; She, J. Modern Study of Traditional Chinese Medicine; Xue Yuan Publisher: Beijing, China, 1999.

12. Joo, J.; Lee, D.; Wu, Z.; Shin, J.H.; Lee, H.S.; Kwon, B.M.; Huh, T.L.; Kim, Y.W.; Lee, S.J.; Kim, T.W.; et al. In vitro metabolism of obovatol and its effect on cytochrome P450 enzyme activities in human liver microsomes. Biopharm. Drug Disposit. 2013, 34, 195. [CrossRef] [PubMed]

13. Woodbury, A.; Yu, S.P.; Wei, L.; Garcia, P. Neuro-modulating effects of honokiol: A review. Front. Neurol. 2013, 4, 130. [CrossRef] [PubMed]

14. Ito, K.; Iida, T.; Ichino, K.; Tsunezuka, M.; Hattori, M.; Namba, T. Obovatol and obovatal, novel biphenyl ether lignans from the leaves of Magnolia obovata THUNB. Chem. Pharm. Bull. 1982, 30, 3347. [CrossRef] [PubMed]

15. Matsuda, H.; Kageura, T.; Oda, M.; Morikawa, T.; Sakamoto, Y.; Yoshikawa, M. Effects of constituents from the bark of Magnolia obovata on nitric oxide production in lipopolysaccharide-activated macrophages. Chem. Pharm. Bull. 2001, 49, 716. [CrossRef] [PubMed]

16. Jun, Y.; Jian, G.W.; Jin, Y.W.; Yan, B.W. Quality evaluation of the leaves of Magnolia officinalis var. biloba using high performance liquid chromatography fingerprint analysis of phenolic compounds. J. Separ. Sci. 2016, 39, 784 .

17. Teponno, R.B.; Kusari, S.; Spiteller, M. Recent advance in research on lignans and neolignans. Nat. Prod. Rep. 2016, 33, 1044. [CrossRef] [PubMed]

18. Hartini, Y.S.; Nugroho, L.H. The accumulation of two neolignan in the leaves, stems, and flower of red betel (Piper crocatum Ruiz \& Pav.). J. Phys. Conf. Series 2017, 835, 012017.

19. Simpson, S.A. Other Plant Metabolites. In Pharmacognosy; Elsevier: Amsterdam, The Netherlands, 2017; Chapter 12.

20. Kim, S.Y.; Kim, J.; Jeong, S.-I.; Jahng, K.Y.; Yu, K.-Y. Antimicrobial effects and resistant regulation of magnolol and honokiol on methicillin-resistant Staphylococcus aureus. BioMed Res. Int. 2015, 2015, 283630. [CrossRef] [PubMed]

21. Yongjin, H.; Jinling, Q.; Xi, Z.; Changrong, G. Antimicrobial effect of Magnolia officinaliss extract against Staphylococcus aureus. J. Sci. Food Agric. 2011, 91, 1050.

22. Harborne, J.B. Phytochemical Methods: A Guide to Modern Techniques of Plant Analysis; Chapman \& Hall: London, UK, 1998.

(C) 2020 by the authors. Licensee MDPI, Basel, Switzerland. This article is an open access article distributed under the terms and conditions of the Creative Commons Attribution (CC BY) license (http://creativecommons.org/licenses/by/4.0/). 